\title{
The use of C3d as a means of monitoring clinical activity in systemic lupus erythematosus and rheumatoid arthritis
}

\author{
W. J. W. MORROW,$^{1}$ D. J. P. WILLIAMS,$^{1}$ C. FEREC,$^{2}$ R. CASBURN-BUDD ${ }^{1}$ \\ D. A. ISENBERG,$^{3} \mathrm{E}$. PAICE, ${ }^{3} \mathrm{M}$. L. SNAITH, ${ }^{3} \mathrm{P}$. YOUINOU, ${ }^{2 *}$ AND \\ P. LE GOFF ${ }^{2}$ \\ From the ${ }^{1}$ Department of Immunology, Middlesex Hospital Medical School, London; ${ }^{2}$ Laboratoire \\ d'Immunologie, Centre-Hospitalier-Universitaire, Brest, France; and the ${ }^{3}$ Department of Rheumatology, \\ University College Hospital, London
}

SUMMARY Plasma samples from 44 patients with systemic lupus erythematosus (SLE) and 43 with rheumatoid arthritis (RA) were assayed for C3d, a breakdown product of the third component of complement (C3), which was also measured in parallel. Levels of C3d varied in direct proportion with disease activity in RA, whereas C3 showed little change. Although C3d values also increased with worsening clinical condition in SLE, this trend was not considered to be sufficiently clear to be useful and did not provide any advantage over the routinely performed C3 assay.

The problems of assessing clinical activity in systemic lupus erythematosus (SLE) by monitoring immunological parameters have been discussed. ${ }^{1}$ In particular the lack of any measurement that would reliably reflect the severity of the disease was noted; thus improvement in objective testing is needed.

Low plasma C 3 levels can be used as an approximate indicator of increasing clinical activity in SLE, ${ }^{2-4}$ although this trend is not as clear for rheumatoid arthritis (RA) ${ }^{56}$ However, it is possible that variations in $\mathrm{C} 3$ levels may occur for reasons other than complement consumption; for example an increased synthetic rate may accompany an accelerated catabolism. ${ }^{6}$ In such instances measured values may bear little relation to the severity of disease. C3d, a fragment generated from activated C3, may be more closely related to an inflammatory process, and initial investigations ${ }^{78}$ suggested that the measurement of this component may provide valuable clinical information. This study attempts to evaluate the usefulness of $\mathrm{C} 3 \mathrm{~d}$ measurements for the assessment of clinical activity in SLE and rheumatoid arthritis (RA).

Accepted for publication 3 December 1982.

Correspondence to Dr W. J. W. Morrow, Cancer Research Institute, School of Medicine, University of California, San Francisco, California 94143, USA.

* Present address: Department of Immunology, Middlesex Hospital Medical School, London.

\section{Patients, materials, and methods}

$S L E$ patients. Each patient had 4 or more of the criteria for the classification of SLE as defined by the American Rheumatism Association. ${ }^{9}$ Patients were grouped according to clinical status (inactive, slightly active, moderately active, severely active) as defined in Table 1. Only one plasma sample was taken from any one patient on one instance in any particular clinical grade.

$R A$ patients. RA patients were either 'classical' or 'definite' according to the American Rheumatism Association's criteria. ${ }^{10}$ Patients were classified as 'inactive', 'moderately active', or 'severely active' by the method of McCarthy. ${ }^{11}$ Plasma samples were taken from each subject on only one instance regardless of clinical grade.

Blood sampling. Blood samples were collected in standard EDTA tubes and the plasma was stored at $-20^{\circ} \mathrm{C}$ and assayed for C $3 \mathrm{~d}$ within 2 weeks. It has been clearly established that C3d levels do not increase after this time in these storage conditions. ${ }^{12}$ Plasma C3 levels were measured with a laser nephelometer (Hyland Laboratories).

C3d assay. C $3 \mathrm{~d}$ was assayed according to the technique of Perrin et al. ${ }^{7}$ without prior knowledge of the clinical state of the patient. C3d was first separated from the higher molecular weight components of $\mathrm{C} 3$ by incubation of $50 \mu \mathrm{l}$ of plasma with an equal volume of a $22 \%$ solution of polyethylene glycol (PEG 
Table 1 Criteria for grading clinical severity of SLE

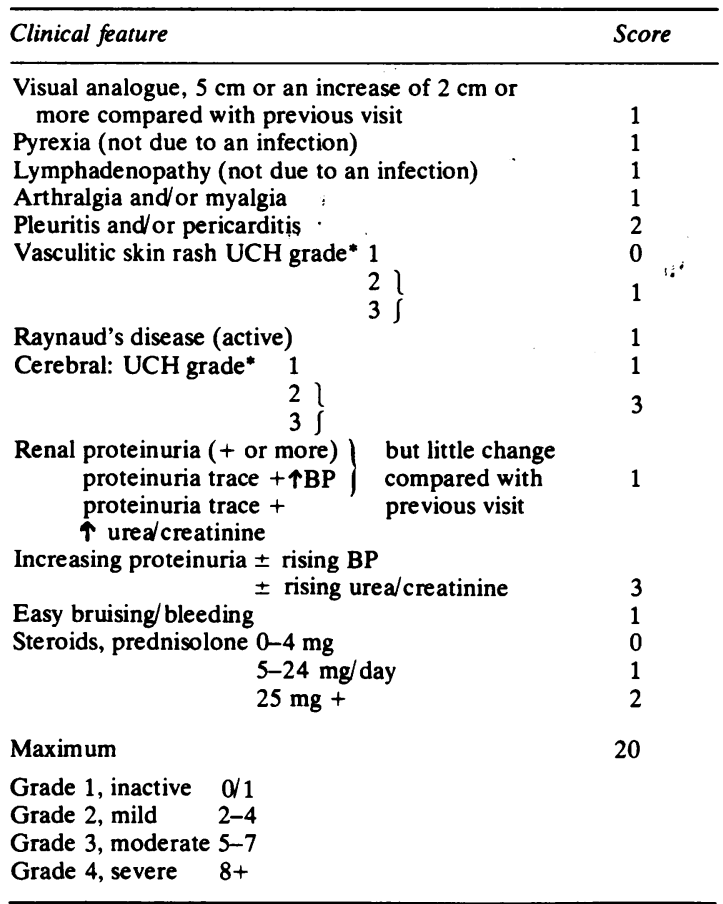

*See reference 1 .

6000 ) in $0 \cdot 1 \mathrm{M}$ Tris-glycine buffer, $\mathrm{pH} 7 \cdot 8$ for 4 hours at $4^{\circ} \mathrm{C}$. After this time the samples were centrifuged and the concentration of $\mathrm{C} 3 \mathrm{~d}$ in the supernatant was estimated by radial immunodiffusion ${ }^{13}$ in $1 \%$ agarose and with $1 \%$ anti-C $3 \mathrm{~d}$ antiserum (Dako).

Diffusion rings were related to a standard curve constructed from dilutions of a pool of normal human serum in which $\mathrm{C} 3 \mathrm{~d}$ had been generated by incubation with cobra venom (Calbiochem) for 48 hours at $37^{\circ} \mathrm{C}$. This sample was considered to be $100 \%$ activated.

Controls. Overall, plasma samples from 59 control subjects ( 38 in Brest, 21 in London) were assayed to

Table 2 Mean C3 and C3d values for SLE patients in each clinical group

\begin{tabular}{lllll}
\hline & $\begin{array}{l}\text { Inactive } \\
\text { (1) }\end{array}$ & $\begin{array}{l}\text { Slightly } \\
\text { active } \\
n=15\end{array}$ & $\begin{array}{l}\text { Moderately } \\
\text { active } \\
(2)\end{array}$ & $\begin{array}{l}\text { Severely } \\
\text { active }\end{array}$ \\
& \multicolumn{5}{c}{$n=31$} & $n=10$ & $\begin{array}{l}(4) \\
n=3\end{array}$ \\
\hline C3 $\mu \mathrm{g} \mathrm{m}^{-1}$ & $1195 \pm 602$ & $1182 \pm 354$ & $1010 \pm 616$ & $809 \pm 263$ \\
C3d \% activity & $27 \pm 9$ & $25 \pm 12$ & $40 \pm 26$ & $31 \pm 4$ \\
\hline
\end{tabular}

The only significant differences in C3d levels were between $(1+2)$ and $(3+4), 0.025<p<0.05$. Identical differences were noted for $\mathrm{C} 3$ levels. establish a normal range for $\mathrm{C} 3 \mathrm{~d}$. These subjects comprised laboratory volunteers and staff attending a fracture rehabilitation clinic. The subjects were matched for age and sex against the patients. All these normal controls had a C3d value below $10 \%$ activation (below curve), and thus an arbitrary value of $15 \%$ activation was assigned as the upper limit of normal for C3d.

Statistics. Data were analysed either by Student's $t$ test or by linear regression, the latter being performed on $\log _{10}$ transformed data.

\section{Results}

C3d levels in 63 plasma samples from 44 patients with SLE (Fig. 1) and 43 with RA (Fig. 2) are given for the various clinical grades. Further analysis is made in Tables 2 and 3, where it can be seen that C3d gave no better indication of clinical status than $\mathrm{C} 3$ in SLE patients. In contrast C $3 \mathrm{~d}$ distinguished well between the clinical grades in RA, although C3 completely failed to do this. In SLE linear regression analysis performed on $\mathrm{C} 3$ and $\mathrm{C} 3 \mathrm{~d}$ values revealed no correlation, either overall or within clinical groups. However, in RA there was a good overall correlation between these 2 parameters in the whole group of patients $(r=0.61, p<0.001)$ and also

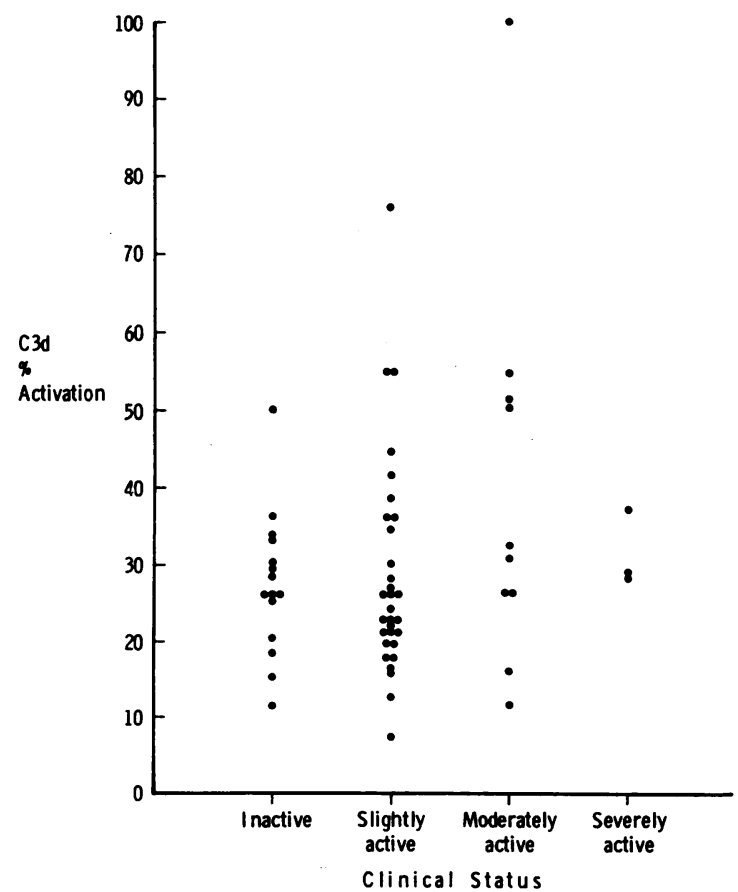

Fig. 1 C3d levels in 59 plasma samples from 44 patients with SLE, grouped according to clinical activity. 


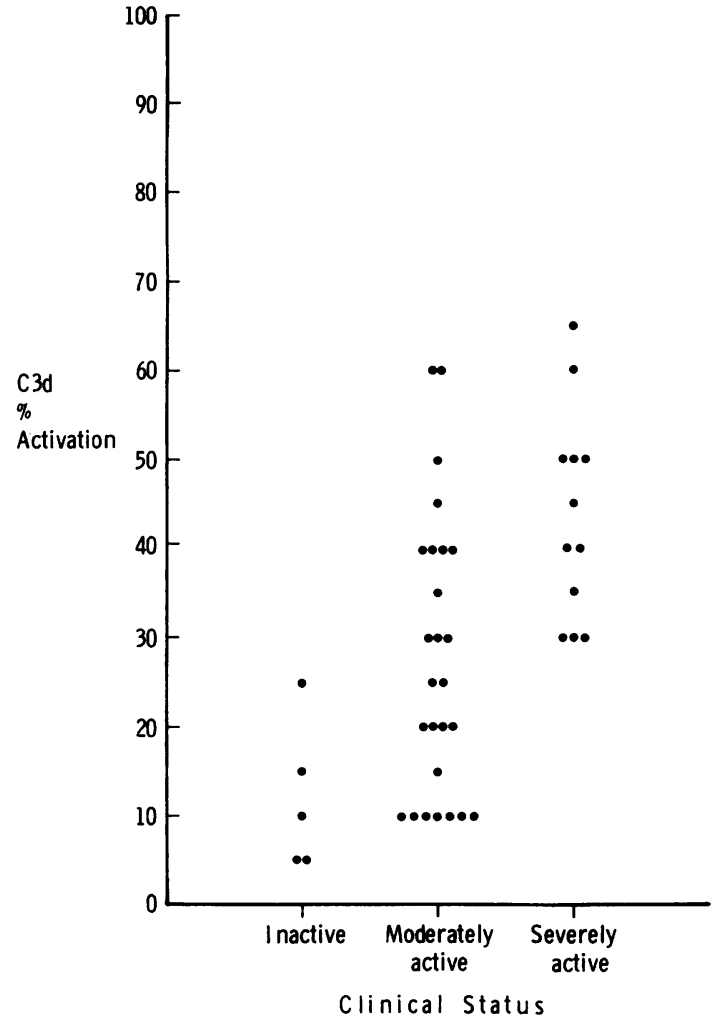

Fig. 2 C3d levels in plasma samples from 43 patients with $R A$, grouped according to clinical activity.

in the moderately active category $(r=0.57, \mathrm{p}<0.05)$ and the severely active group $(r=0.84, p<0.001)$. Furthermore C3d was markedly increased in 5 patients with extra-articular disease (mean $=45 \%$ activation, standard deviation $7 \cdot 1 \%)$, whereas the $\mathrm{C} 3$ value was normal $($ mean $=1510 \mu \mathrm{g} / \mathrm{ml}$, standard deviation $16 \mu \mathrm{g} / \mathrm{ml}$ ). There was no clear association between $C 3 \mathrm{~d}$ levels and pattern of organ involvement in SLE.

Table 3 Mean C3 and C3d values for RA patients in each clinical group.

\begin{tabular}{|c|c|c|c|}
\hline & $\begin{array}{l}\text { Inactive } \\
\text { (1) } \\
n=12\end{array}$ & $\begin{array}{l}\text { Moderately } \\
\text { active } \\
(2) \\
n=26\end{array}$ & $\begin{array}{l}\text { Severely } \\
\text { active } \\
(3) \\
n=5\end{array}$ \\
\hline $\begin{array}{l}\text { C3 } \mu \mathrm{g} \mathrm{ml}^{-1} \\
\text { C3d \% act. }\end{array}$ & $\begin{array}{c}1300 \pm 122 \\
12 \cdot 0 \pm 8 \cdot 3\end{array}$ & $\begin{array}{r}1388 \pm 33 \cdot 7 \\
27 \cdot 5 \pm 15 \cdot 7\end{array}$ & $\begin{array}{c}1520 \pm 420 \\
43 \cdot 75 \pm 11 \cdot 7\end{array}$ \\
\hline
\end{tabular}

Groups 1 and $2, p<0.0025$. Groups 2 and $3,0.005<p<0.01$. There were no significant differences between $\mathrm{C} 3$ levels in any of the clinical groups.

\section{Discussion}

In this study we have shown that C3d levels were clearly raised above normal in both SLE and RA patients, presumably affecting the inflammatory processes involved in these diseases.

C3d levels were associated with the severity of disease in RA and proved to be a much better indicator than C3, which showed no correlation. This finding is in agreement with the data of Mallya et al. ${ }^{14}$ and Nyedegger et al., ${ }^{8}$ who showed that plasma C $3 \mathrm{~d}$ levels correlated with clinical activity, and also with the data of Franco and Schur, ${ }^{5}$ who found that $\mathrm{C} 3$ was rarely below the normal range. It is also of interest to note that $\mathrm{C} 3 \mathrm{~d}$ was particularly increased in patients with extra-articular disease: this was also observed by Nyedegger et al., ${ }^{8}$ Bourke et al. ${ }^{15}$ and Perrin et al. ${ }^{16}$ who found C3d levels raised in synovial fluid from RA patients.

As regards SLE, C3d measurements proved to be of no greater value than $\mathrm{C} 3$ for determining the clinical status of the patients. While both these parameters tended to change with worsening of disease, this trend, though statistically significant, was not considered to be sufficiently clear to be useful. The latter result is perhaps a little surprising, as these components have been said to show an inverse correlation in SLE. ${ }^{7}$ Perrin et al. ${ }^{7}$ showed that C3d was increased in SLE in an inverse relationship with C3 but did not comment on the association between $\mathrm{C} 3 \mathrm{~d}$ and clinical activity except in 2 selected case studies. It is possible that we did not establish a clear trend because of the diverse nature of the disease in our patients. We could not analyse the data further according to the principal clinical features such as arthralgia, renal, cerebral, and dermatological symptoms owing to the small numbers of subjects in these subgroups. It is quite possible that there was a relationship between C3d and clinical status in those patients with kidney disease, as other investigations would appear to suggest that high levels of C $3 \mathrm{~d}$ are associated with nephritis. ${ }^{77}$ A larger sample might clarify this issue.

In contrast to SLE, the correlation between $\mathrm{C} 3$ and C3d was very marked in RA, particularly in the severely active groups, though no explanation can be offered for this. Thus routine $\mathrm{C} 3 \mathrm{~d}$ measurements would appear to be of value for monitoring the clinical progress of RA patients, though our data indicate that this parameter offers little useful information in the case of the SLE patient.

The authors thank Miss Queenie Jayawardena for excellent secretarial assistance. W. J. W. M. and D. A. I. were supported by the Sir Jules Thom Charitable Trust. P. Y. is a recipient of an award from La Fondation pour la Recherche Médicale. 


\section{References}

1 Morrow W J W, Isenberg D A, Todd-Pokropek A, et al. Useful laboratory measurements in the management of systemic lupus erythematosus. $Q J$ Med 1982; 202: 125-38.

2 Gewurz H, Pickering R J, Mergenhagen S E, et al. The complement profile in acute glomerulonephritis. Contrasts and experimental correlations. Int Arch Allergy Appl Immunol 1968; 34: 556-70.

3 Kohler P F, Ten Bensel R. Serum complement component alterations in acute glomerulonephritis and systemic lupus erythematosus. Clin Exp Immunol 1969; 4: 191-202.

4 Schur P H. Complement testing in the diagnosis of immune and autoimmune diseases. Am J Clin Pathol 1977; 68: 647-58.

5 Franco A R, Schur P H. Hypocomplementemia in rheumatoid arthritis. Arthritis Rheum 1971; 14: 231-8.

6 Schur P H, Austen K F. Complement in human disease. Ann Rev Med 1968; 19: 1-24.

7 Perrin L H, Lambert P H, Miescher P A. Complement breakdown products in plasma from patients with systemic lupus erythematosus and patients with membrano-proliferative or other glomerulonephritis. J Clin Invest 1975; 56: 165-76.

8 Nyedegger U E, Zubler R H, Gabay G, et al. Circulating complement breakdown products in patients with rheumatoid arthritis. J Clin Invest 1977; 59: 862-8.

9 Cohen A S, Reynolds W E, Franklin E C, et al. Preliminary criteria for the classification of systemic lupus erythematosus. Bull Rheum Dis 1971; 21: 643-8.
10 Ropes M W, Bennet G A, Cobb S, et al. Revision of diagnosis criteria for rheumatoid arthritis. Bull Rheum Dis 1958; 9: 175-6.

11 McCarthy D J. Clinical assessment of rheumatoid arthritis. In: McCarthy D J, Hollander J L, eds. Arthritis and allied conditions. 9th ed. Philadelphia: Lea and Febiger, 1979: 131-47.

12 Bourke B E, Moss I K, Maini R N. Measurement of the complement C3 breakdown product $\mathrm{C} 3 \mathrm{~d}$ by rocket immunoelectrophoresis. J Immunol Methods 1982; 48: 97-108.

13 Mancini G, Carbonara A O, Heremans J F. Immunochemical quantification of antigens by single radial immunodiffusion. Immunochemistry 1965; 2: 235-54.

14 Mallya $\mathrm{R} \mathrm{K}$, Vergani D, Tee D E H, et al. Correlation in rheumatoid arthritis of concentrations of plasma C3d, serum rheumatoid factor, immune complexes and $\mathrm{C}$-reactive protein with each other and with clinical features of disease activity. Clin Exp Immunol 1982; 48: 747-53.

15 Bourke B E, Moss I K, Mumford P, et al. The complement fixing ability of putative circulating immune complexes in rheumatoid arthritis and its relationship to extra-articular disease. Clin Exp Immunol 1982; 48: 726-732

16 Perrin L H, Nyedegger U E, Zubler R H, et al. Correlation between levels of breakdown products of $\mathrm{C} 3, \mathrm{C} 4$, and properdin factor $B$ in synovial fluids from patients with rheumatoid arthritis. Arthritis Rheum 1970; 20: 647-52.

17 Lagrue G, Branellec A, Intrator L, et al. Evaluation du C3d dans les néphropathies glomérulaires chroniques primitives. Nouv Presse Med 1979; 8: 1153-6. 